\title{
Seismogenic tectonics of the Qian-Gorlos earthquake in Jilin Province, China
}

\author{
Jun Shen $\cdot$ Bo Shao $\cdot$ Xiao-hui Yu $\cdot$ Yang Yu $\cdot$ Gao Qi • \\ Mei Deng $\cdot$ Hanwen Zhang
}

Received: 9 October 2015/Accepted: 16 March 2016/Published online: 22 April 2016

(C) The Author(s) 2016. This article is published with open access at Springerlink.com

\begin{abstract}
The Qian-Gorlos earthquake, which occurred in the Songliao basin in Jilin Province in 1119 AD, was the largest earthquake to occur in NE China before the 1975 Haicheng earthquake. Based on historical records and surface geological investigations, it has been suggested previously that the earthquake epicenter was in the Longkeng area. However, other workers have considered the epicenter to be in the Halamaodu area based on the landslides and faults found in this region. No seismogenic structure has yet been found in either of these two regions. We tried to detect active faults in the urban areas of Songyuan City, where the historical earthquake was probably located. One of the aims of this work was to clarify the seismogenic structure so that the seismic risk in the city could be more accurately evaluated. The area was investigated and analyzed using information from remote sensing and topographic surveys, seismic data from petroleum exploration, shallow seismic profiles, exploratory geological trenches on fault outcrops, and borehole data. The geophysical data did not reveal any evidence of faults cutting through Cretaceous or later strata under the Longkeng scarp, which has been suggested to be structural evidence of the Qian-Gorlos earthquake. The continuous fault surfaces on the back edge of terraces in the
\end{abstract}

J. Shen · B. Shao $(\bowtie) \cdot X$. Yu · G. Qi · M. Deng · H. Zhang Institute of Disaster Prevention, Langfang 065201, China e-mail: 632975575@qq.com

X. Yu

Institute of Geology, China Earthquake Administration, Beijing 100029, China

Y. Yu

Lanzhou Institute of Seismology, China Earthquake

Administration, Lanzhou 730000, China
Halamaodu area stretch for $>3.5 \mathrm{~km}$ and were probably formed by tectonic activity. However, results from shallow seismic profiles showed that the faults did not extend downward, with the corresponding deep structure being identified as a gentle kink band. A new reverse fault was found to the west of the two suggested epicenters, which presented as a curvilinear fault extending to the west, and was formed by two groups of NE- and NW-trending faults intersecting the Gudian fault. Three-dimensional seismic and shallow seismic data from petroleum exploration revealed its distinct spatial distribution and showed that the fault may cut through Late Quaternary strata. Exploration boreholes and later geomorphological studies provided further proof of this. Based on these results and analysis, the Gudian fault was confirmed as having been an active fault since the Late Quaternary, with the possibility of earthquakes of magnitude $>7$ in the future. The QianGorlos earthquake was most probably the result of breakage on one or two sections of this $66-\mathrm{km}$-long fault.

Keywords Qian-Gorlos earthquake · Historical earthquake $\cdot$ Seismogenic structure

\section{Introduction}

There was a great earthquake in the southern part of the Songliao basin in February of the third year of the Tianfu period under the reign of Emperor Jin Taizu in the Jin Dynasty (1119 AD) (Li 1960; Gu 1983; Office of Central Earthquake Working Group 1971). The earthquake is recorded in The History of Great Jin in a total of 24 Chinese words: "In the first month of the lunar year, in the third year of the Tianfu period (1115-1234 AD) under the reign of Emperor Jin Taizu, on Shixing of Zhaozhou and 
Lishe of Longzhou, happened an earthquake and accompanying land subsidence. Thousands of people died." Wu et al. (1988) determined the distribution of the earthquake intensity and concluded that the earthquake magnitude was close to 7 and the epicentral intensity was VIII degrees on the China Seismic Intensity Scale based on the historical records and surface geological investigations. Based on the laws of seismic wave propagation and attenuation, the area with an earthquake intensity of VII degrees was located between the present day cities of Nongan and Tahucheng. After delineating the line of earthquake destruction, $\mathrm{Wu}$ et al. (1987) found a linear scarp and springs in the Longkeng area, a giant ditch and spring to the SE of Taohaotai, and horizontal tilted $\mathrm{Q}_{4}$ strata. These three features led them to conclude that the Longkeng area was the epicenter of the $1119 \mathrm{AD}$ earthquake. However, $\mathrm{Li}$ et al. (1999a) found no direct evidence of the existence of this fault after field investigations and suggested that the scarp and springs in the Longkeng area were not caused by an earthquake, but were erosional landforms; the horizontal tilted $\mathrm{Q}_{4}$ strata were also interpreted as terrain features.

Based on an analysis of historical data, Tang (1986, $1988,1990)$ considered the epicentral intensity of the earthquake as IX degrees (magnitude $6^{3} / 4$ ) and the epicenter of the earthquake to be in the Halamaodu area. The reasons for this conclusion were (1) there were a large number of landslides in the Halamaodu area; and (2) probable fault activity was observed in Late Pleistocene strata, which might be part of the so-called Second Songhua river fault.

Zhou and Gao (1992) analyzed the earthquake tectonics of the $1119 \mathrm{AD}$ earthquake and pointed out that the faults were discontinuous in the Halamaodu area; they also raised some questions about the scale and activity of the Second Songhua river fault through field surveys. The survey by $\mathrm{Li}$ et al. (1999a, b) of the Second Songhua river fault, especially the regional gravity field data and partial geophysical prospecting and drilling data, proved that small surface ruptures and large landslides in this zone were mainly of secondary origin and that the landslides were multi-phase. Both ancient and modern landslides were recorded and the scarps on both sides of the Second Songhua river did not have a fault origin.

It can be seen from this discussion that there are a number of different interpretations about the epicenter of the 1119 AD Qian-Gorlos earthquake in Jilin and there are only large-scale observations of its seismogenic tectonics. The structural region is located on the boundary between the southeastern uplift and the central concave area of the Songliao basin, where seismic energy was easily accumulated ( $\mathrm{Li}$ et al. 1999a, b; Fu and He 1999; Gao 2008). Multiple episodes of suspected tectonic activity occur at the intersection of different geological units $(\mathrm{Li}$ et al. 1999a, b, 2012) (Fig. 1).
The study of historical earthquakes depends on detailed historical records. It is also necessary to fully understand the evolution of the administrative zones in China. There are many dynasties in the history of China with a complex evolution and the geographical divisions are very different from the present day (Chao et al. 2012). As a result, the magnitude and epicenter of the earthquake are difficult to accurately define with the available records. In general, special seismic geological and geophysical studies are required to locate the corresponding seismogenic structures and to combine these with historical records to determine the earthquake epicenter.

The seismogenic structures are the geological structures related to the build-up and occurrence of the seismic event and generally refer to active faults, folds, and basins. It is necessary to find seismogenic structures on a corresponding scale and with similar attributes in historical earthquake research. The major task in the detection of active faults and the evaluation of seismic risk in urban areas is to find evidence of the seismogenic structures of historical earthquakes in or near the target area. Detailed geological and geophysical background information obtained during the search for active faults can play a key role in evaluating seismic risks (Guidoboni et al. 2000; Galadini 2009; Bottari et al. 2009; Galli and Bosi 2002; Zhai et al. 2009).

We searched for active faults in Songyuan city, Jilin Province in 2012, with the aim of evaluating the present day risk of a seismic event. The determination of the seismogenic structure of the Qian-Gorlos earthquake in $1119 \mathrm{AD}$ was one of the most important research aims. This earthquake is important in proving the intensity of fault activity and therefore the location of seismogenic structures and studies of the characteristic geometry and kinematics are important steps in evaluating the seismic risk in Songyuan City.

This work consisted of a combination of geological and geophysical exploration at the two possible epicenters of the historical earthquake. Oil exploration data were used to investigate the existence of other possible epicenters. Our work differs from that of Li et al. (1999b) and Zhou and Gao (1992) in that we carried out not only more detailed geological and landform survey work, but also used information from geophysical exploration and boreholes. Reliable evidence showing the position, attributes, and characteristics of the seismogenic tectonics were acquired.

\section{Study of potential seismogenic structures}

2.1 Geological landform survey and geophysical studies in the Longkeng area

An east-west-trending scarp, east of Hada mountain on the west bank of the Second Songhua river, from west of 


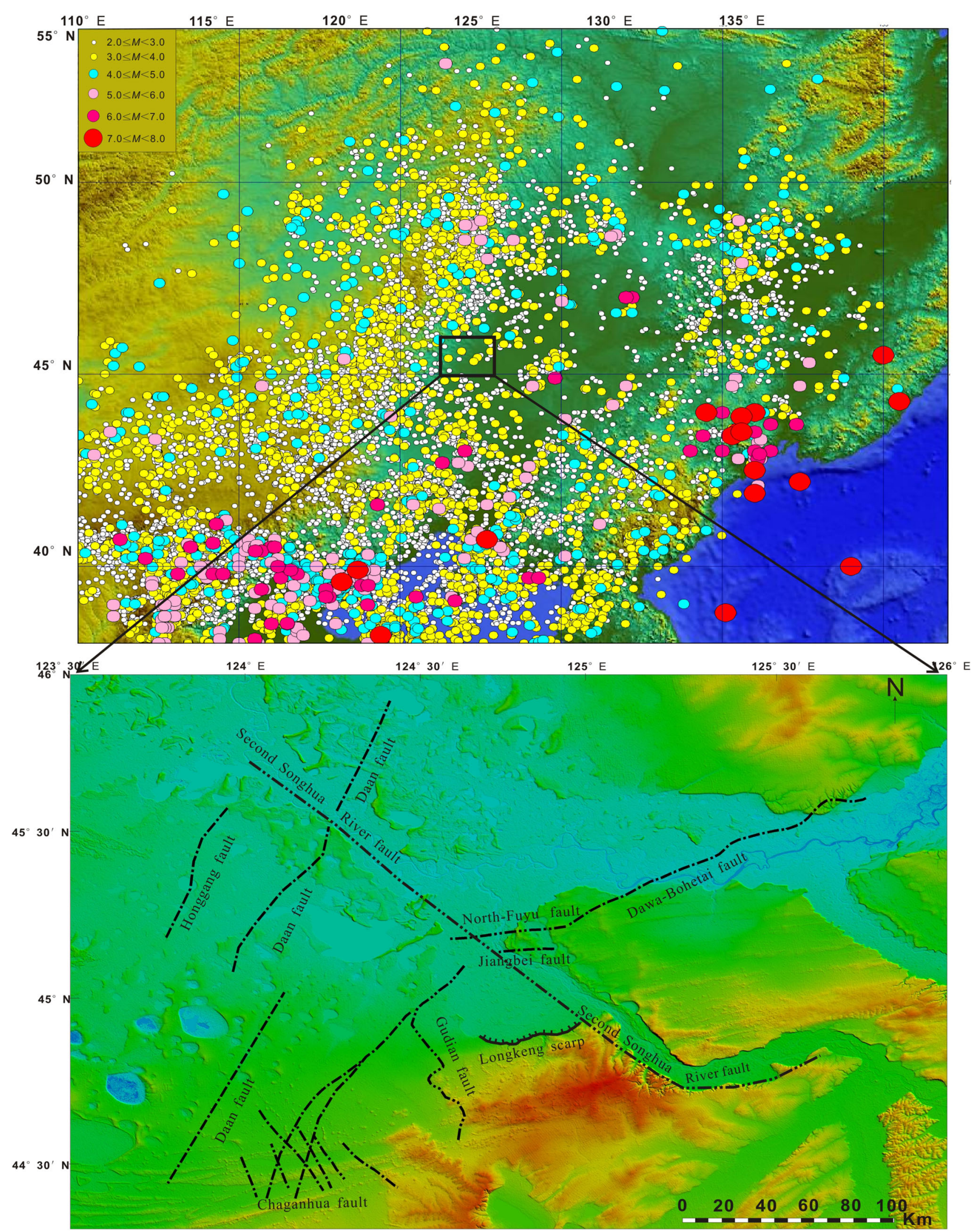

Fig. 1 Regional seismicity and faults distribution; The yellow oval is the proposed iso-seismic curve of the Qian-Gorlos earthquake, confirmed by the position Noan and Tahucheng; three white-name faults in the curve range are the suspected target seismogenic structures of the earthquake 
Taohaotai and extending to Gudian, is in the center of the Tahucheng and Nongan areas (Fig. 2a). The scarp is about $50-\mathrm{km}$ long and forms the boundary between the southern high plain and the northern low plain. Cretaceous outcrops can be seen in the south, covered by the $\mathrm{Q}_{1}$ gravel layer of the Baitushan Group and partly covered on the top by $\mathrm{Q}_{3}$ eolian sandy soil. The elevation of the high plain is $>200 \mathrm{~m}$ and the highest point is $250 \mathrm{~m}$. Where the low plain is at an altitude of $140 \mathrm{~m}$, there is a nearly $25-100 \mathrm{~m}$ drop (Fig. 2b). The low plain is covered by middle-late Quaternary strata $>40 \mathrm{~m}$ thick; on the high plain, the strata are very thin and consist of weathered material and eolian accumulations, showing that the high platform formed after the end of $Q_{1}$. Since the middle-late Quaternary, there may have been a significant vertical differential movement between the high and low plains and the flat scarp between the two plains may have been an active fault.

Multiple springs are distributed along the E-W scarp and one of the most typical is at Longkeng. Longkeng is a natural ravine, situated at Taohaotai in Songyuan, Jilin Province, with length of $2500 \mathrm{~m}$, width of $300 \mathrm{~m}$, and depth $>70 \mathrm{~m}$. Both sides of the ravine are steep walls formed of a gravel layer of the $Q_{1}$ Baitushan Group, which is rich in salts and vulnerable to dissolution. A deep groove is found below the water table, so that springs and erosion by underground water are severe along the ditch. After being affected by erosion, the thickness of the Baitushan Group sediments was reduced. Both sides of the ravine collapsed, intensifying the surface erosion and promoting the development of gullies. This surface landform resembles the changes in terrain caused by great earthquakes. For example, the magnitude $M_{\mathrm{s}} 8.0$ Wenchuan earthquake in 2008 caused mountains and rivers to change, exacerbating the natural evolution of the landscape by strengthening external geological processes. Based on similar observations, Wu et al. (1988) considered the Longkeng area in Taohaotai to be the epicenter of the 1119 AD Qian-Gorlos earthquake.

We carried out detailed investigations along the eastwest-trending scarp. We collected, processed, and analyzed high-resolution optical remote sensing images and satellite radar terrain data for the region, carefully analyzing the geometrical distribution and profile form of the scarp and comparing these features with those of fault scarps with a typical active tectonic origin. The geometric distribution and morphological analysis of the scarp showed that it is very straight and cuts through topographic and geomorphological units. It seems to extend to the east side of the Second Songhua river.

We did not find any large fault planes in the continuous strata after surveying the Cretaceous strata across the scarps near Hada Mountain along the west bank of the Second Songhua river. These scarps had small fractures or cleavages with only small displacements. The fault planes were on the scale of tens of centimeters and were filled with gypsum. Therefore, these faults were not formed in the Middle or Late Quaternary.

Detailed investigations were carried out on the northsouth-trending groove cutting the east-west-trending scarp from west of Hada Mountain to west of Taohaotai. The gullies formed from the Late Pleistocene to the Holocene. Gullies in the Late Pleistocene were wide with the accumulation of thick layers of eolian and secondary loess. Gullies in the Holocene were long, narrow, and steep, with rudimentary debris, thus favoring denudation. Springs were exposed near to the mountain pass; the Longkeng area springs are typical representatives. Faults and folds were not seen in the intersection between the gullies and scarps. As a result of the eolian origin of the Late Pleistocene and Holocene strata, the accumulation of slope at a certain angle may not be the result of deformation by tectonic movements. Wu (1991) suggested that the scarp terrain was the result of erosion and that it was not associated with the seismogenic structure of the Qian-Gorlos earthquake.

Particular investigations were carried out on the formation of the springs and their possible relationship with the Qian-Gorlos earthquake along the Longkeng ditch. Based on this research, we suggest that the gullies developed in the $\mathrm{Q}_{1}$ gravel layer of the Baitushan group. Both sides of the walls are steep, with several springs along the gully. There was a large flow of water resembling a creek. The $\mathrm{Q}_{1}$ stratum where the springs are exposed is loose as a result of dissolution and is prone to collapse, forming a ledge. The surface water quickly transported the eroded mater to the lower reaches. Therefore, the combined effect of both the surface and underground water caused gullies to develop quickly with strong retrogressive erosion. This phenomenon was not been found along the ditches that contained faults, fault-related deformation of strata, and concentrated distributions of joints. It was therefore difficult to show that the gullies developed by the springs were associated with active tectonics.

Therefore, although a scarp nearly $50-\mathrm{km}$ long exists in the landscape and is likely to have been formed by fault activity, no evidence of faulting was found in the survey of geological landforms. Whether the fault exists required information about tectonic activity at depth. The following three studies were therefore undertaken.

(1) Images of the distribution of the deep tectonic structures determined by the petroleum and geological departments in earlier studies were collected. A fault with the same trend was not shown in the scarp zone in any other work, apart from an early report that noted the scarp as a fault.

(2) The north-south- and east-west-trending seismic reflection profiles of Longkeng obtained during 

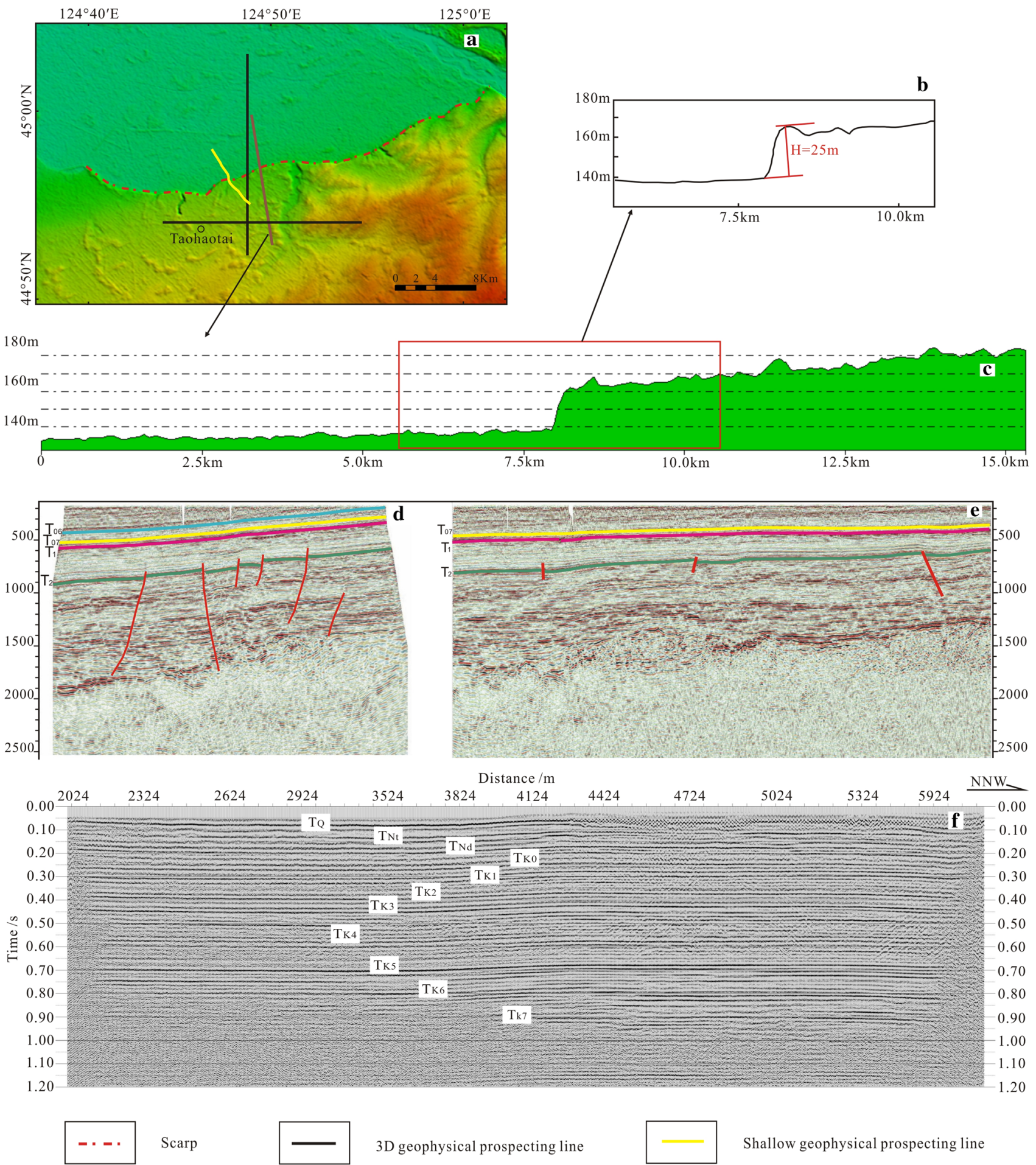

Fig. 2 Landform, three-dimensional, and shallow geophysical profiles across the Longkeng scarp. a Landform and position of geophysical profiles of the Longkeng scarp, $\mathbf{b}$, $\mathbf{c}$ north-south difference in height, $\mathbf{d}$, e the east-west and north-south three-dimensional geophysical profiles from Jilin Oilfield and $\mathbf{f}$ shallow geophysical profile across the scarp

petroleum exploration were assembled (Fig. 2d, e). The strata of the north-south-trending profile are flat and slightly tilted to the north; the upper strata are continuous and show no obvious fault. The strata of the east-west-trending profile are obviously tilted; they are also complete and show no faults. 
(3) The observation that the formation is tilted rather than faulted showed the existence of folds and uplifts. It was difficult to determine whether the uplifts are currently active because the shallow structural information had been removed from the seismic reflection profiles. There was therefore a need to determine the shallow structural characteristics of the Longkeng area to see whether the Quaternary strata had also been tilted. Shallow seismic exploration data obtained using an artificial seismic line was therefore overlain on the petroleum data.

A survey line was laid along a country road in a direction of roughly $157^{\circ}$ and with a length of $3840 \mathrm{~m}$; it began in the south near Xinantun. Eleven groups of reflection waves (with a migration time $<1200 \mathrm{~ms}$ ) had obvious characteristics and are described in the following.

The shallow artificial seismic exploration profile (Fig. 2f) shows the strata pitching toward the north on the whole, with the south being higher than the north, and less apparent dip along the direction of the line. A fold structure exists in the central section, which makes the strata in the north uplift slightly. The strata are first distributed in the horizontal direction and pitched to the north as the northern edge of the profile was approached; the apparent dip was still small. The reflected wave had no obviously disordered waveform nor any disconnected distortion in the line ups. However, an obvious fold could clearly be seen under the central survey line and the surface of the Quaternary strata in particular simultaneously showed a fold deformation. Therefore, the shape of the fold edge was formed in the Quaternary and should still be present. The terrain scarps seen at the surface were not completely the same as those that Li et al. (1999b) thought were formed by erosion. The formation of this fold is a very useful piece of information.

\subsection{Geological landform survey and geophysical investigations in the Halamaodu area}

Large-scale landslides and normal faults have developed on the mountain west of Halamaodu, about $30 \mathrm{~km} \mathrm{SE} \mathrm{of}$ Songyuan city and located near the west bank of the Second Songhua river. Zhou and Gao (1992) regarded this as evidence of fault activity on the Second Songhua river fault, associated with the Qian-Gorlos earthquake in 1119 AD. Zhang (1987) identified the Second Songhua river fault from remote sensing data and partial geological data. Li et al. (1999a, b) inspected these fault outcrops separately and suggested that they were all of landslide origin, placing doubt on the existence of the Second Songhua river fault. However, Li et al. (2002) and Yang et al. (2010) still supported the existence of the fault and produced abundant evidence of this; they considered the fault to be the seismogenic structure of the $1119 \mathrm{AD}$ earthquake. The affected strata listed by Li et al. (2002) and Yang et al. (2010) were mainly concentrated in fault outcrops in Halamaodu. The faults had a wide distribution range. Intertwined with modern landslides, it was hard to distinguish between the cause and results of the landslides and faults. We invited a number of experts to consider this problem. The following plans were proposed: (1) investigate the distribution of faults; (2) study the deep structures; and (3) analyze the cause of the faults. The work was divided into two parts: a geological survey and geophysical exploration work.

\subsubsection{Fault distribution}

Zhou and Gao (1992) surveyed the faults in the Halamaodu area and reported typical outcrops. Li et al. (1999b) proposed that these outcrops were a result of landslides. The distribution of the faults was not given. QuickBird satellite images with a resolution of $0.6 \mathrm{~m}$ were purchased to determine the distribution of the faults in combination with the surface investigations (Fig. 3a).

The western town of Halamaodu is located on the slope front between a high plain and the first terrace of the Second Songhua river (a relatively low plain). The high plain is $>200 \mathrm{~m}$ above sea level and the low plain is around $140 \mathrm{~m}$ above sea level. A sandy gravel layer of the $\mathrm{Q}_{1}$ Baitushan group with a thickness of ca. 20-40 m has accumulated on the high plain, the base of which is Cretaceous mudstone. A layer of weathering crust containing limonite has developed between the Cretaceous mudstone and the gravel layer of the Baitushan Group. The Cretaceous strata form a water-resistant layer, which could easily be a landslide surface. The sandy gravel layer of the Baitushan group contains a large amount of soluble salts, which makes the strata vulnerable to collapse. The landslides are currently dispersed in six large ditches located on the central part of the trailing edge of the terraces. There is a clear round-backed armchair structure and obvious faults on the trailing edge of the landslides (Fig. 3c).

We focused on the scarp shoulder, away from the faults of the modern landslides, to avoid including scattered faults of obvious landslide origin. Six outcrops were found in total. Three were exposed by the recent headward erosion of gullies and were some distance from the modern landslides. The fault outcrops were studied carefully; nearvertical surface scratches were found on normal faults and no horizontal dislocation was seen. A longer stretch of scarp could be seen, along which two rows of hand-holds were set to confirm whether there were any faults between outcrops to determine the distribution of the fault. The faults were distributed in a right-step en echelon manner with a total length of $3.5 \mathrm{~km}$. The faults were located on 


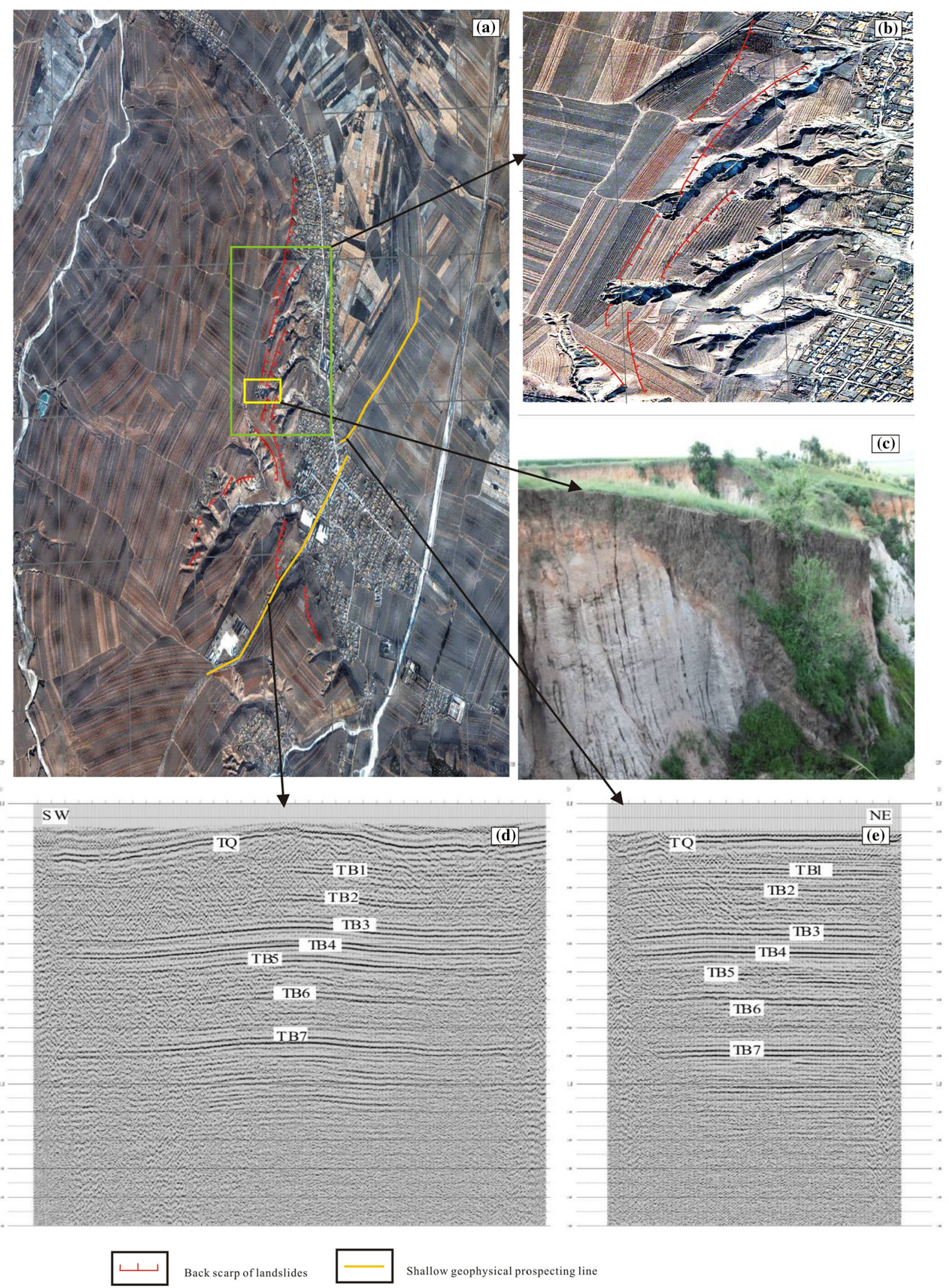

Fig. 3 a, b QuickBird satellite images and partial enlarged view of the landslides in Halamaodu area, c obvious fault outcrops on the trailing edge of the landslides, and $\mathbf{d}$, e shallow geophysical profiles across the landslides in the Halamaodu area 
the top of the slope of the leading edge of the high plain, almost on the platform.

These faults extended further and wider than the landslides in the region, which is inconsistent with the scale and position in space of the modern landslides. The fault outcrops are very similar to the active faults, so it is not surprising that many seismo-geologists have regarded this area as the Second Songhua river fault and evidence of the seismogenic tectonics of the Qian-Gorlos earthquake. Whether the faults are active or not, it is hard to make a convincing judgment based on the surface geology. The deeper structure must be investigated to understand the deeper extension of the faults.

\subsubsection{Deep tectonics}

In the absence of three-dimensional seismic data for the area, we collected data from the departments of geology and petroleum from the 1950s to the 1990s; no fault was shown in the Halamaodu area. On the basis of these geological surveys, we studied the deep structure of this area.

Two seismic and high-density electrical detection lines were laid across the fault. The seismic exploration used a 48-way seismograph with a 2-m spacing, 24-way rolling receiving, and 18-pound tapping source, as developed by Jilin University. As a result of the low seismic detection energy, we could only see potentially abnormal faults without any clear information on the down-thrown side. High-density electrical detection used a 60-way system with a battery power supply developed by the Chongqing Geological Instrument Factory; 5 and 2-m track pitches were used. Shallow information is clearly visible using such a high-density electrical method, but accurate evidence on fault overspreading down was lacking.

We therefore laid an artificial seismic exploration line across the area using an 18 ton hypocenter truck as the source. The line was nearly NE-trending and crossed the southern endpoint of the Halamaodu landslide group. As a result of restrictions from the wiring, the line was divided into two segments of lengths 2310 and $1095 \mathrm{~m}$ to control the positions passed by the fault.

Seven groups of reflections with obvious characteristics are interpreted on the profile (Fig. 3d, e). Based on the wave group characteristics combined with geological data for the region, the $\mathrm{Q}$ reflection interface was suggested to be the base of the Quaternary. An anticline is seen on the TB3-TB7 reflection interface. The TQ reflection interface shows signs of uplift caused by denudation in the Halamaodu area. The strata had reflection continuity; no disorder was found in the reflection wave groups, and there was no distortion or break in the line ups, or any other obvious sign of faulting. However, there was a fold uplift; the shape and amplitude of the uplift in the upper and lower strata were basically identical. Therefore, this is thought to be a relatively new uplift that occurred after the accumulation of the upper strata.

Thus, it can be seen that a relatively wide flat uplifting fold exists under the faults and landslide groups in Halamaodu rather than deep faults. The possibility of the fold structure being the seismogenic structure of the QianGorlos earthquake is not high. Normal faults in the Halamaodu area should be shallow faults formed by the ancient landslides rather than the seismogenic structure.

\subsection{Discovery and study of the Gudian Active Fault}

During our work to detect active faults in the urban area of Songyuan, which began in 2012, a new Late Pleistocene active fault was found SW of downtown Songyuan and was named the Gudian fault. This had not been mentioned in previously published research from the seismological department. A number of papers from the petroleum department had mentioned the Gudian fault. Liu et al. (2007) also studied the activity of the reverse Gudian fault. Using shallow seismic reflection profiles and drilling exploration, we found evidence of the fault's activity since the Late Quaternary.

In this location, the Gudian fault is attached to the FuyuZhaodong fault zone on the western side of the Fuyu swell in the central depression zone of the Songliao basin (Fig. 4a). Under the influence of the southeasterly uplift, seen on the three-dimensional seismic reflection section, the Gudian fault was formed by the intersection of two groups of NE- and NW-trending faults, assuming a westerly extending arc. The north wing of the arc is NEtrending and is equivalent to the middle section of the Fuyu-Zhaodong fault zone (Fig. 4c) and therefore, the Gudian fault is regarded as part of this fault zone. From analysis of the seismic profiles and the deep terrain gradient, the Gudian fault is seen to be more active than the main body of the fault zone. The fault is about $66-\mathrm{km}$ long on the seismic profiles from petroleum exploration and consists of two continuous arcs. The eastern GaizijingGuyang arc is $28.5-\mathrm{km}$ long, while the Guyang-Shenjingzi arc is $20-\mathrm{km}$ long. Based on the continuous underground fault length, if the Gudian fault was active in the Late Quaternary, then it had the ability to cause a magnitude 7 earthquake. Seismic reflection profiles from the Jilin Oilfield showed that the fault trended to the east and had a loose base and a steep upper side (Fig. 4d). The fault is normal on the down-thrown side and thrust on the upthrown side. The lower normal fault formed in an earlier period of depression and then experienced an inversion (Chen and Chen 1996).

Because the shallow structural information had been removed from the petroleum seismic reflection profile, 


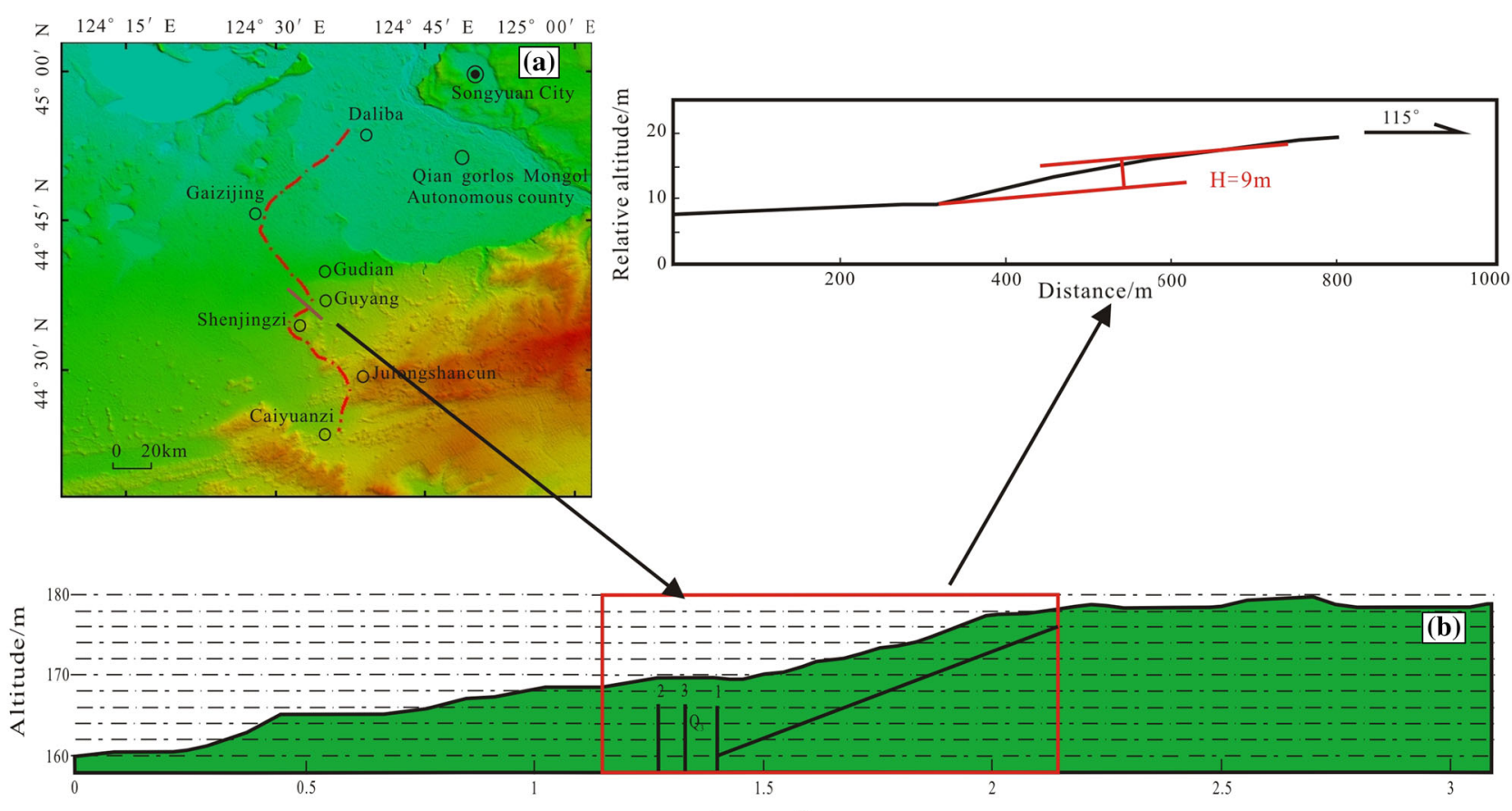

Distance $/ \mathrm{km}$

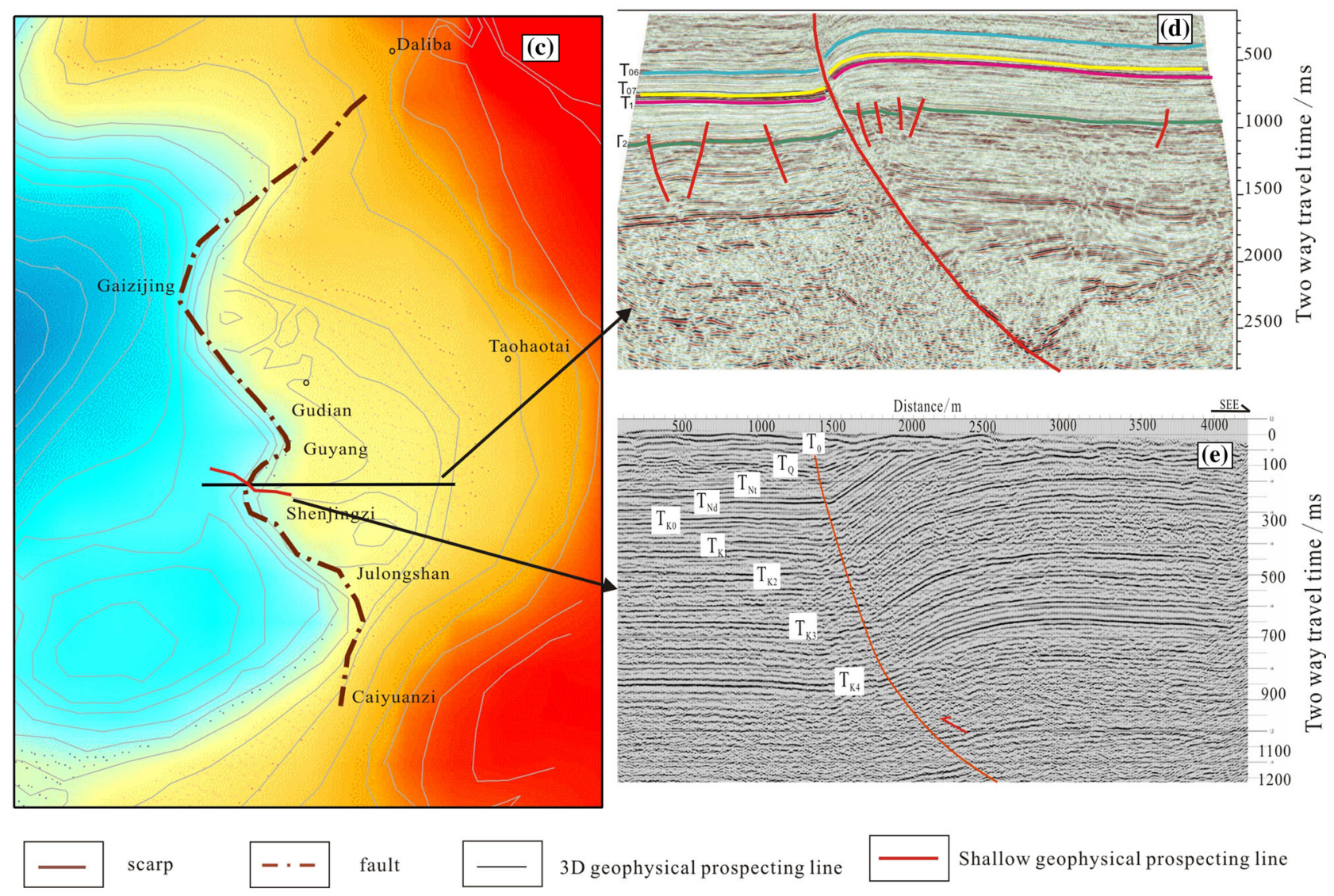

Fig. 4 Landform, three-dimensional, and shallow geophysical profiles of the Gudian fault. a Landform and position of geophysical profiles of the Longkeng scarp, b east-west trending difference in height, $\mathbf{c}$ three-dimensional geophysical plane graph of Gudian fault from Jilin Oilfield, d the east-west three-dimensional geophysical profile extracted from plane graph, and e shallow geophysical profile across the scarp on the position of Shenjingzi 
shallow artificial seismic survey lines and combined drilling exploration were carried out at Shenjingzi, the section with the strongest activity, and an obvious difference in terrain height, to determine the latest activity on the fault.

The shallow seismic reflection profiles showed a steep and east-trending thrust fault in the mid-Quaternary (Fig. 4e). We then laid joint profiles, composed of seven drill wells, which showed that the fault cut the boundary of the light yellow soil layer and the brown yellow soil layer and was embedded at a depth of $24 \mathrm{~m}$. Based on the regional correlation, the light yellow soil represents the Malan Loess, formed in the Late Pleistocene. Therefore, the buried depth of the fault breakpoint is shallower than $24 \mathrm{~m}$. An OSL age of the silt and floury soil samples from the breakpoint was older than $50 \mathrm{ka}$ (the range of OSL is 50,000 a), which is consistent with the regional assumption of Late Pleistocene strata. Fresh cracks were found in the brown loess layer in the borehole, which is circumstantial evidence of new activity by the fault.

From the terrain and landform analysis, an obvious height difference can be seen between the top of the $\mathrm{Q}_{1}$ Baitushan group on both sides of the Gudian fault. On the east side of the fault, the Baitushan group is exposed on the surface; the embedded depth of the $\mathrm{Q}_{1}$ stratum on the west side of the fault is nearly $40 \mathrm{~m}$. With a landform height difference of nearly $10 \mathrm{~m}$, the height difference of the top of $Q_{1}$ is nearly $>60 \mathrm{~m}$. The height difference of the base of $\mathrm{Q}_{3}$ is $>30 \mathrm{~m}$. Therefore, the average vertical displacement of the fault since the Late Pleistocene can be estimated as $0.3 \mathrm{~mm} / \mathrm{a}$, representing only weak activity.

\section{Discussion and conclusions}

The Qian-Gorlos earthquake in 1119 AD occurred in the south-central Songliao basin, which is located in the currently weakly active seismic zone of the central Northeast plain of China. Modern day images of seismic activity show that the epicenter was located in an abnormal belt with a relatively higher active distribution of earthquakes, demonstrating that bigger earthquakes may occur in the region in historical times. Therefore, the corresponding seismogenic structures should be found in the region. Although there is considerable uncertainty about the magnitude of an earthquake that happened 1000 years ago, we used a magnitude of 7 in our work, however, this was not a decisive factor in our research on the seismogenic structure. There are two potential earthquake epicenters in this area and the location of a possible seismogenic structure has been speculated previously. We deduced that the Gudian fault has been an active fault since the late Quaternary.
NNE-trending faults occur on the west bank of the Second Songhua river, together with large-scale landslides, which have been suggested as outcrops of the Second Songhua river fault by some researchers and also as the seismogenic structure of the Qian-Gorlos earthquake. Landslides along the river have also been related to the earthquake. However, some researchers have suggested that the faults in the Halamaodu zone were of landslide origin and that the Second Songhua river fault is not an active fault. Although a detailed surface geology survey was carried out to determine the extension and movement characteristics of the fault, it could not be confirmed whether the fault had been formed by landslides. Deep tectonic information from geophysical exploration showed that corresponding deep faults do not exist, so there are no seismogenic structures of the Qian-Gorlos earthquake in this location.

The Gudian fault is to the west of the two suggested epicenters and is seen on seismic sections as a curvilinear fault extending to the west and formed by the intersection of two groups of NE- and NW-trending faults. The early normal fault later transformed into a thrust fault, on which thrust movement continues to this day. Seismic exploration and drilling exploration have revealed that late Quaternary accumulations of sediments are cut by the fault. Fresh fractures were found in drilling cores, probably formed by historical earthquakes.

The Gudian fault is the most active section of the NEtrending Fuyu-Zhaodong fault zone in the southern Songliao basin. Several magnitude 5 earthquakes occurred in the SW of the Songliao basin in 2006 and 2013, showing that the fault zone is currently active. Small modern earthquakes occur at high frequency near the NE section of the Fuyu-Zhaodong fault zone north of the Gudian fault. The Gudian fault has fewer modern earthquakes than the rest of the fault zone, which is probably a result of the release of energy by the great earthquake of 1119 . The release of energy is incomplete on both the north and south sides and continued release today is seen as a higher level of seismic activity.

Based on these results and analyses, we confirm that the Gudian fault is the seismogenic structure of the QianGorlos earthquake. Considering the nondeterminacy of historical earthquakes research, the earthquake was probably the result of breakage of one or two sections of the 66-km-long thrust fault.

Acknowledgments This work was supported by the National Natural Science Foundation of China under Grant No. 41372216, the Major Projects of the Ministry of Finance under Grant No. 201108001, the Fundamental Research Funds of the Central Universities under Grant No. 20120102 and No. ZY20150303, and the Teachers Fund of China Earthquake Administration under Grant No. 2012001 
Open Access This article is distributed under the terms of the Creative Commons Attribution 4.0 International License (http://crea tivecommons.org/licenses/by/4.0/), which permits unrestricted use, distribution, and reproduction in any medium, provided you give appropriate credit to the original author(s) and the source, provide a link to the Creative Commons license, and indicate if changes were made.

\section{References}

Bottari C, Stiros S, Teramo A (2009) Archaeological evidence for destructive earthquakes in Sicily between 400 BC and AD 600 . Geoarchaeology 24:147-175

Chao H, Diao S, Wang Z (2012) Textual research of the Qi-chu earthquake of $179 \mathrm{BC}$ and discussion on its seismogenic structure. Seismol Geol 2:211-227 (in Chinese with English abstract)

Chen Z, Chen F (1996) Kinematic characteristics of inversion structures in Songliao basin. Geoscience 10(3):99-105 (in Chinese with English abstract)

$\mathrm{Fu}$ W, He R (1999) Structural characteristics of earthquakes in Songliao basin and its peripheral regions. Glob Geol 2:98-103 (in Chinese with English abstract)

Galadini F (2009) Defining the causes of ancient building collapse (structural decaying vs. seismic shaking) in archaeological deposits of central Italy. Il. Quaternario 22(1):73-82

Galli P, Bosi V (2002) Paleoseismology along the Cittanova fault: implications for seismotectonics and earthquake recurrence in Calabria (southern Italy). J Geophys Res 107:1-19

Gao L (2008) Structural environment of Songliao basin and characteristics of seismic activity in northeast China region. Earthquake 4:59-67 (in Chinese with English abstract)

Gu G (1983) Catalogue of earthquakes in China (1831 BC-1969 AD). Science Press, Beijing (in Chinese)

Guidoboni E, Muggia A, Valensise G (2000) Aims and methods in territorial archaeology: possible clues to a strong fourth century $\mathrm{AD}$ earthquake in the Straits of Messina (southern Italy). In: McGuire WJ, Griffiths DR, Hancock PL, Stewart IS (eds) The Archaeology of Geological Catastrophes, vol 171. Geological Society, London (Special Publications), pp 45-70

Li S (1960) Catalogue of earthquakes in China. Science Press, Beijing (in Chinese)

Li C, Wang Y, Shen J, Zhang L, Li C (1999a) Discussion on new activity of the second Songhuajiang fault. Seismol Geol 21(4):351-360 (in Chinese with English abstract)

Li C, Wang Y, Zhang L, Li Z, Li C (1999b) Causative tectonic conditions of the historic earthquake $\left(M=6^{3} / 4\right)$ in 1119 in
Songyan area. Earthq Res China 15(3):41-50 (in Chinese with English abstract)

Li Z, Zhao C, Guo M (2002) Analysis of the Second Songhua River fault activities. Jilin Geol Z1:15-19 (in Chinese with English abstract)

Li E, Liu C, Zhang L, Zeng Z (2012) The correlation of structure and earthquake in Songliao Basin. Prog Geophys 4:1337-1349 (in Chinese with English abstract)

Liu Z, Chen B, Li Z (2007) Preliminary study on scenario earthquake and seismological disaster of Songyuan City, Jinlin Province. Seismol Res Northeast China 1:67-73 (in Chinese with English abstract)

Office of Central Earthquake Working Group (1971) Catalogue of earthquakes in China. Science Press, Beijing (in Chinese)

Tang Y (1986) The magnitude calculation and determination of the Kalamu earthquake in February 1119 in Qianguo, Jilin. Seismol Res Northeast China 2(01):43-48 (in Chinese with English abstract)

Tang Y (1988) The determination of earthquake epicenter in Jinlin Province, 1119. Remote Sens Inf 1:27-29 (in Chinese with English abstract)

Tang Y (1990) Three essential factors of a severe earthquake in Qian Guo of Jin Lin Province in February, 1119. J Northeast Normal Univ (Nat Sci) 3:151-159 (in Chinese with English abstract)

Wu G (1991) The study and the analysis of historical earthquake material in north-east China. Seismol Res Northeast China 1:17-24 (in Chinese with English abstract)

Wu G, Fang H, Li Z, Fang M (1987) The textual research on "zhaozhoushixing" and "longzhou lishe" earthquake, 1119. Seismol Res Northeast China 2:35-41 (in Chinese with English abstract)

Wu G, Fang H, Li Z, Fang M (1988) The investigation and study of Qianguo earthquake, 1119. Seismol Res Northeast China 4(1):67-76 (in Chinese with English abstract)

Yang Q, Wang J, Liu Z, Wu Z, Cheng B (2010) Geological features and Quaternary activity of the second Songhua River fault. Earthq Res China 1:34-45 (in Chinese with English abstract)

Zhai Y, Cheng H, Ren J, Zhou Y (2009) The neo-tectonic motion around Halamaodu of Qian'guo County, Jinlin Province. Jilin Geol 3:6-10 (in Chinese with English abstract)

Zhang Z (1987) The characteristics of the Songhua-Jiang Fault activity and preliminary discussion on the cause of seismicity in the Yitong-shulan Fault. Seismol Res Northeast China 3:73-79 (in Chinese with English abstract)

Zhou B, Gao M (1992) The structural analysis of several moderatestrong earthquakes in basins. Seismol Geol 14(2):145-150 (in Chinese with English abstract) 